Z. Klin. Chem. Klin. Biochem.

13. Jg. 1975 , S. $225-229$

\title{
Desmosterol Accumulation in Rats with Experimental Myotonia
}

\author{
By D. Seiler, W. Fiehn and E. Kuhn \\ Medizinische Poliklinik der Universität Heidelberg
}

(Eingegangen am 2. Oktober 1974/26. Februar 1975)

\begin{abstract}
Desmosterol is found in various organs of rats that show signs of myotonia in their skeletal muscle as a result of treatment with 20.25diazacholesterol. The amount of desmosterol depends on the time of treatment, and is different in different organs and different kinds of muscle. The increase in desmosterol is much lower and the rats do not show any signs of myotonia when fed a cholesterol rich diet in addition to treatment with 20.25-diazacholesterol. Treatment with triparanol also causes desmosterol accumulation but in these rats myotonia is rarely observed.
\end{abstract}

Our results suggest that in the experimental animals myotonia becomes manifest when every second cholesterol molecule of the muscle cell membrane is replaced by desmosterol. This is easily achieved in animals fed with 20.25 -diazacholesterol but rarely occurs with triparanol.

In verschiedenen Organen von Ratten, die mit 20.25-Diazacholesterin behandelt ivurden und eine myotone Reaktion der Skelettmuskulatur zeigen, kann Desmosterin nachgewiesen werden. Der Desmosteringehalt hängt von der Behandlungsdauer ab und variiert von Organ zu Organ. Auch die verschiedenen Muskeltypen zeigen Unterschiede.

Verfütterung einer cholesterinreichen Diät zusätzlich zur Behandlung mit 20.25-Diazacholesterin führt zu einem geringeren Desmosterinanstieg. Gleichzeitig wird auch die myotone Reaktion der Skelettmuskulatur verh indert.

In den Organen von Ratten, die mit Triparanol behandelt wurden, läßt sich ebenfalls Desmosterin nachweisen, eine Myotonie kann aber nur in seltenen Fällen gefunden werden.

Unsere Ergebnisse lassen den Schluß zu, daß bei den behandelten Tieren myotone Reaktionen beobachtet werden können, wenn jedes zweite Cholesterinmolekül der Muskelzellmembran durch Desmosterin crsetzt ist. Dies kann sehr leicht durch Gabe von 20.25-Diazacholesterin erreicht werden, während eine Behandlung mit Triparanol nur in seltenen Fällen zu einem so hohen Desmosterinanteil führt.

20.25-Diazacholesterol (Fig. 1 a) was synthesized for the first time by Counsell et al. (1). These authors reported the influence of the substance on cholesterol biosynthesis. 20.25-Diazacholesterol inhibits the last step of cholesterol biosynthesis, the reduction of desmosterol to cholesterol, resulting in accumulation of desmosterol in liver (1) and serum (2) of rats treated with this substance. Also an alteration of the fatty acid pattern of membranal phospholipids was shown (3).

In 1959 triparanol (Fig. 1 b) was also shown to inhibit the interconversion of desmosterol and cholesterol (4). Bricker et al. (5) reported desmosterol accumulation in serum and liver. They also reported the disappearance of desmosterol in the treated rats by feeding a high cholesterol diet.

While 20.25-diazacholesterol was shown to be able to induce myotonia (6) and to aggravate already existing myotonia (7), such an effect was not described for triparanol (8).

In this study we present kinetic data on the replacement of cholesterol by desmosterol in several organs of rats treated with 20.25-diazacholesterol and triparanol. We further present evidence for the role of desmosterol incorporation in the development of the myotonic reaction of skeletal muscle.<smiles>CCN(CC)CCOc1ccc(C(O)(Cc2ccc(Cl)cc2)c2ccc(C)cc2)cc1</smiles>

Fig. 1. Structural formulae of 20.25-diazacholesterol (a) and triparanol (b). 


\section{Methods}

In each of 2 series of experiments $\mathbf{4 0}$ male Wistar rats with an initial body weight of $160-170 \mathrm{~g}$ were divided into four groups. The control group was treated daily with $0.2 \mathrm{ml}$ water by an esophageal tube; the rats referred to as 20.25-diazacholesterol

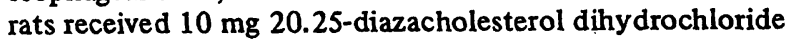
dissolved in $0.2 \mathrm{ml}$ water per day, and the triparanol rats received a suspension of $20 \mathrm{mg}$ triparanol in $0.2 \mathrm{ml}$ water per day. These three groups were maintained on a standard rat diet.

The fourth group was also given $10 \mathrm{mg}$ 20.25-diazacholsterol dihydrochloride in $0.2 \mathrm{ml}$ water per day but was fed with a cholesterol rich diet $(2 \mathrm{~g}$ cholesterol $/ 100 \mathrm{~g}$ standard diet).

After treatment for the number of days indicated in the figs. a series of four rats consisting of one rat from each group was anesthesized by ether, subjected to electromyography (for details of the method see 1.c. (7)) and then bled by puncture of the abdominal aorta. The organs were quickly excised, minced with scissors and homogenized in an Ultra-Turrax Mixer at $0^{\circ} \mathrm{C}$. The erythrocytes separated from the plasma were washed three times with ice-cold $9 \mathrm{~g} / 1 \mathrm{NaCl}$.

After freeze-drying of the homogenates and erythrocyte suspensions respectively the lipids were obtained quantitatively by a threefold extraction with $20 \mathrm{vol}$. chloroform/methanol (volumes, $20 \mathrm{ml}+10 \mathrm{ml}$ ) for one hour at room temperature. According to Sperry (9) the lipids were purified, in one aliquot of the extract the total sterol content was determined according to the Zak method (10) as modified by Winer et al. (2), in another aliquot the sterols were separated from the other lipids by thin-layer chromatography on silica gel with chloroform as solvent and were then eluted from the scraped off silica gel with chloroform/methanol (volumes, $20 \mathrm{ml}+10 \mathrm{ml}$ ). The percentage of cholesterol and desmosterol was determined by a gas-liquid chromatographic procedure in a Varian-aerograph 1400 using a $2 \mathrm{ft}$. column with $3 \%$ OV-17 on 120 mesh Chromosorb Q: $250^{\circ} \mathrm{C}$ isotherm, $\mathrm{N}_{2}=36 \mathrm{ml} / \mathrm{min}$; FID. This procedure permits a clean separation of cholesterol and desmosterol (fig. 9), both substances giving the same molar response as could be proved by the use of commercially available standards (Merck, Darmstadt resp. Sigma, St. Louis). The peaks were quantified by triangulation. 20.25-Diazacholesterol was a gift from G. D. Searle, Chicago, USA. Triparanol was a gift from Merell Pharma, GroßGerau.

\section{Results}

The total sterol content of various tissues of the control rats can be seen from the table 1 . As there were no significant differences in the total sterol content in the different groups of rats the values for the other three groups are not shown in detail.

The increase of desmosterol in the sterol fraction of the liver of the various groups of rats is shown in figure 2 . The desmosterol content of ery throcytes and lung increases similarly. Therefore the latter results are not shown in detail. There was no desmosterol in the control rats.

In the first weeks a linear increase of desmosterol is observed reaching a plateau after about 20 days of treatment. At that time the sterol fraction consists of about $88 \%$ desmosterol and even after treatment for 250 days no further increase could be found in these organs.

In rats treated with triparanol such values were never reached, but a plateau in the curve can also be seen after treatment for about 20 days,

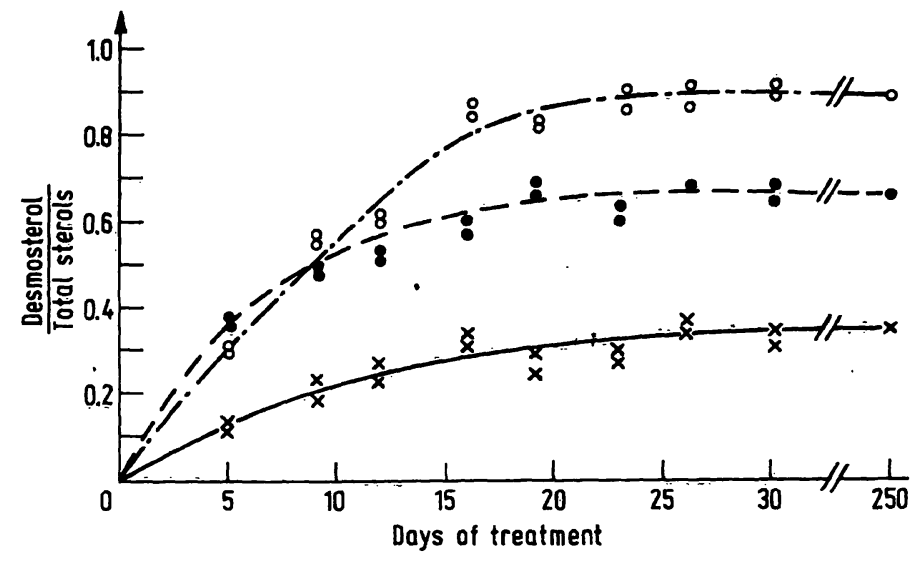

Fig. 2. Desmosterol increase in liver dependent on time of treat-. ment

0-.---o 20.25-diazacholesterol treated rats

$x \longrightarrow x \quad 20.25$-diazacholesterol treated rats receiving a high cholesterol diet $(20 \mathrm{~g} / \mathrm{kg})$

- - - triparanol treated rats

Since a cholesterol rich diet inhibits endogenous cholesterol biosynthesis, desmosterol accumulation is reduced. This clearly can be seen from the results obtained with rats which received 20.25-diazacholesterol and a $2 \%$ cholesterol diet. Although the total sterol content remained unchanged in this group of rats, $38 \%$ desmosterol in the sterol fraction of the above mentioned organs was the maximal value observed.

For the kidney the results are shown in figure 3. Again triparanol treatment was not as effective in exchanging

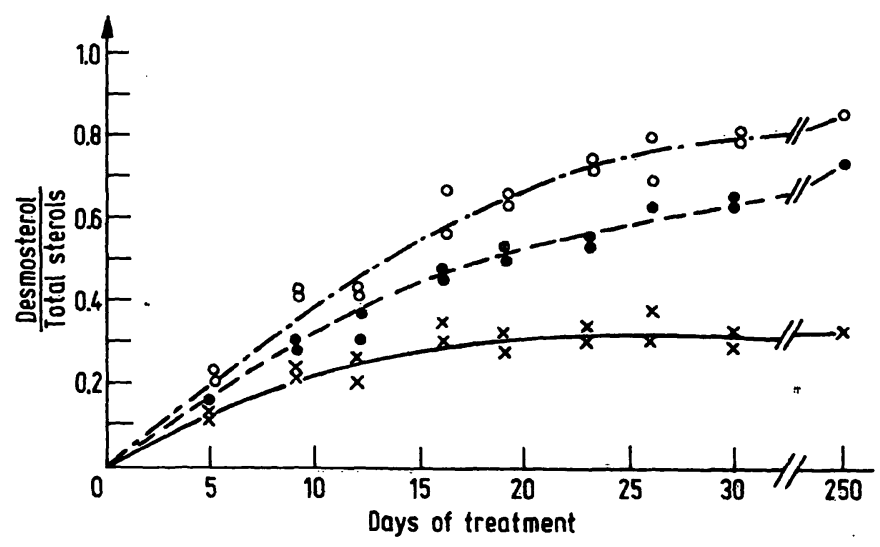

Fig. 3. Desmosterol increase in kidney dependent on time of treatment. Symbols see fig. 2.

Tab. 1. Total sterol content (mg/g wet weight \pm S.D.) in different tissues and in erythrocy tes $(\mathrm{mg} / \mathrm{ml}$ red blood cells) of control rats. $(n=18)$

Liver

Lung

$2.85 \pm 0.21$

Kidney

$4.35 \pm 0.26$

M. rectus femoris

$4.02 \pm 0.23$

Heart

$0.89 \pm 0.05$

M. soleus

$1.55 \pm 0.05$

N. ischiadicus

$1.70 \pm 0.07$

Brain

$23.70 \pm 0.38$

Erythrocytes

$0.93 \pm 0.10$ 
cholesterol for desmosterol but the preventive effect of a cholesterol rich diet is found also for this organ.

Desmosterol accumulation in the different kinds of muscles can be seen in figures 4-6. In all groups of rats the highest desmosterol percentages are found in $M$. rectus femoris, which is a fast-twitch white muscle (11), and in the heart, whereas in M. soleus (slow-twitch intermediate muscle) the desmosterol content increases somewhat more slowly, the maximum incorporation being the same at the end of the experiment.

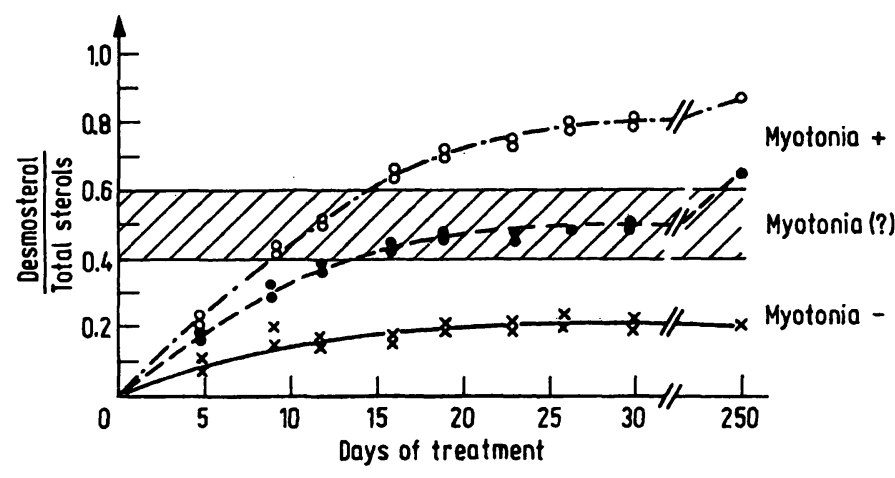

Fig. 4. Desmosterol increase in M. rectus femoris dependent on time of treatment. Symbols see fig. 2.

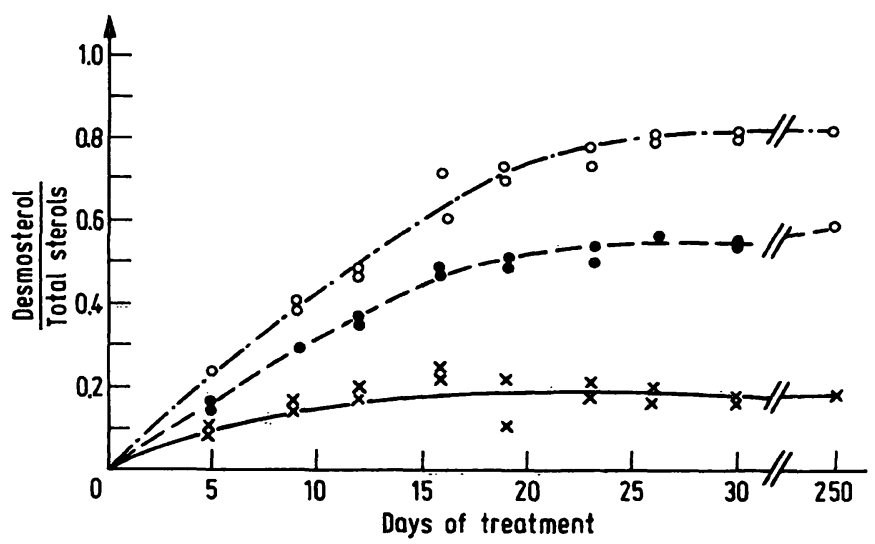

Fig. 5. Desmosterol increase in heart muscle dependent on time of treatment. Symbols see fig. 2.

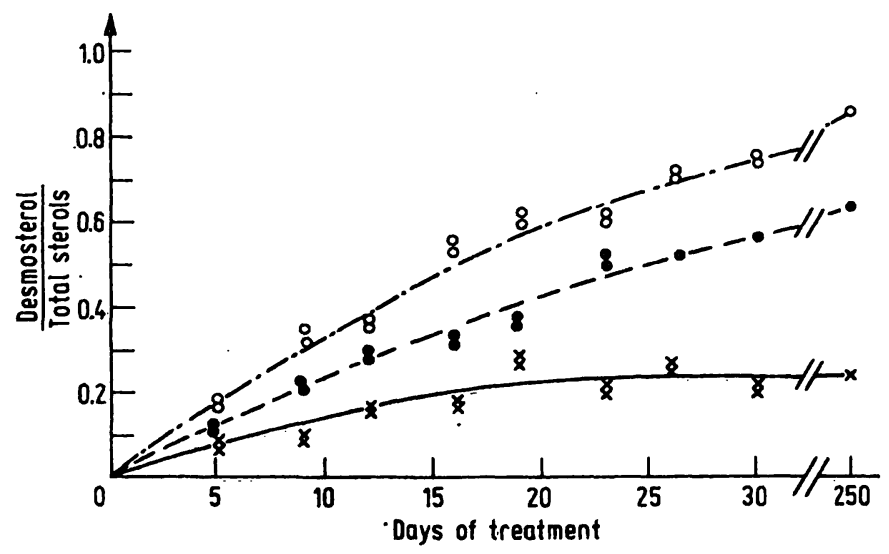

Fig. 6. Desmosterol increase in M. soleus dependent on time of treatment. Symbols see fig. 2.
As in the other organs of the triparanol treated rates, the desmosterol content of the muscles is less than in the 20.25-diazacholesterol treated rats, and the preventive effect of a cholesterol rich diet can also be seen in all the muscles. Typical myotonic discharges in the electromyogram could be demonstrated in the $M$. rectus femoris of those animals that had a desmosterol percentage higher than $60 \%$, regardless of whether this percentage was due to feeding 20.25-diazacholesterol or triparanol; while for the animals with muscle desmosterol in the range of about 40 to $60 \%$ (shaded in fig. 4) a short lasting spontaneous activity was found in the electromyogram.

A much different behaviour with regard to cholesterol replacement by desmosterol can be seen in the brain (fig. 8) and in the peripheral nerve (fig. 7). The increase in desmosterol is very slow and, therefore, differences between the three groups are not easily seen. Both nervous tissues, i.e. brain and peripheral nerve, behaved almost identically. Even after a 250 days treatment the desmosterol content in brain and peripheral nerve is only about $41 \%$ of total sterols for 20.25 -diazacholesterol treated rats, $29 \%$ for the triparanol rats, and, as in other organs, feeding a cholesterol rich diet additionally diminishes the amount of incorporated desmosterol (24\%) after this time.

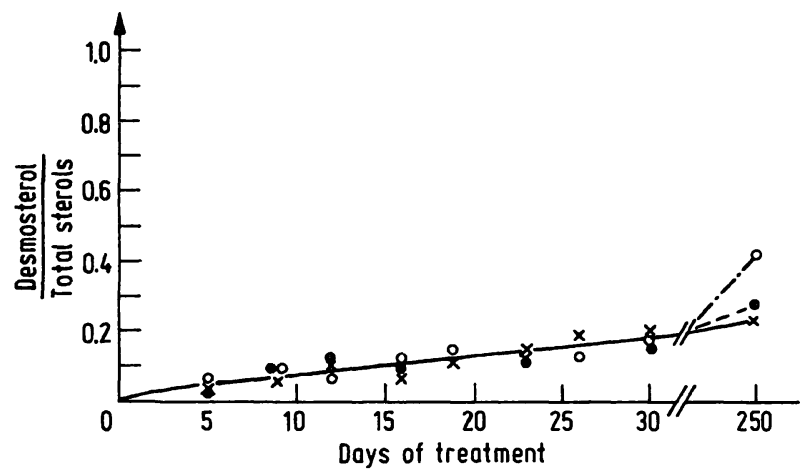

Fig. 7. Desmosterol increase in $\mathrm{N}$. ischiadicus dependent on time of treatment. Symbols see fig. 2. The results for the second series of rats were identical and are not shown here.

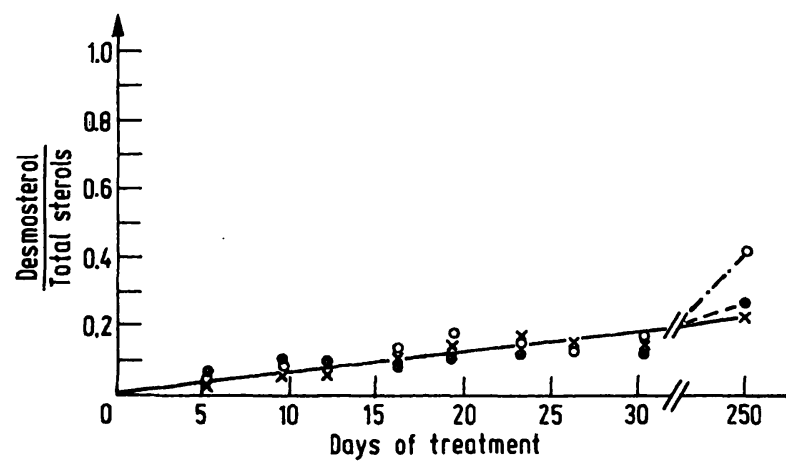

Fig. 8. Desmosterol increase in the brain dependent on time of treatment. Symbols see fig. 2. The results for the second series of rats were identical and are not shown here. 


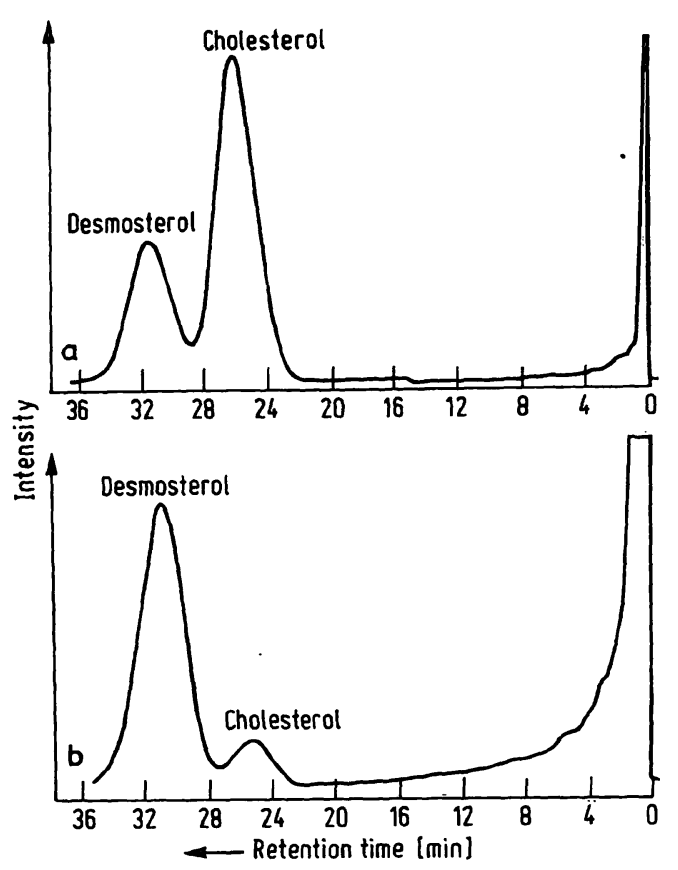

Fig. 9. Gas-chromatographic separation of cholesterol and desmosterol in peripheral nerve (m. ischiadicus).
((a), $\left.\frac{\text { desmosterol }}{\text { total sterols }}=0.404\right)$ and
skelatal muscle (m. rectus femoris)
((b), $\frac{\text { desmosterol }}{\text { total sterols }}=0.851$ )
of rats treated with 20.25-diazacholesterol for 250 days.

Figure 9 clearly demonstrates the differences in sterol composition between skeletal muscle and nervous tissue of a rat treated for 250 days with 20.25 -diazacholesterol.

\section{Discussion}

From the results of our experiments it can be clearly seen that various organs behave differently with regard to desmosterol accumulation after inhibition of desmosterol reductase by 20.25 -diazacholesterol and triparanol. The reason for this is not known. One could imagine that replacement of cholesterol depends on the amount of cholesterol originally present in the tissues. This could explain the tremendously slow exchange that was found in brain and peripheral nerve, for the content of cholesterol in nervous tissues is about 6-7 times higher than in the other investigated tissues, such as liver and kidney (Tab. 1).

This could also explain the differences between fasttwitch-white (i.e. M.rectus femoris) and slow-twitchintermediate (i.e. M. soleus) muscle, for it was shown that the cholesterol content in various species is higher in the slow-twitch-intermediate fiber than in the fasttwitch white fiber (1.c. (12), and Tab. 1). Our findings also reflect the rate of cholesterol turnover known to be rather rapid in the liver, slower in tissues like muscles and almost non-existent in nervous tissue, but we do not know anything about the different affinities of different tissues for cholesterol and desmosterol, respectively. The finding that the desmosterol increase in triparanol treated rats is.lower than in 20.25-diazacholesterol treated rats may be due to, the fact that triparanol is much less water soluble and can only be given as a suspension and that triparanol is more toxic than 20.25-diazacholesterol. We therefore did not succeed in feeding rats with more than $20 \mathrm{mg}$ triparanol daily.

As early as 1966 Winer (8) suspected a participation of desmosterol in the appearance of myotonic symptoms in skeletal muscle, but he thought that additional factors would have to be present, because in his experiments triparanol failed to provoke myotonia.

Our results (fig. 4) are able to explain this discrepancy. Clear cut myotonic discharges in the electromyogram are obtained only when desmosterol makes up more than $60 \%$ of total muscle sterols. It was shown that there is a decrease in the desmosterol percentage from total muscle to muscle cell membrane (13). This would mean that myotonia becomes evident when about every second cholesterol molecile is replaced by desmosterol in the muscle cell membrane. This is easily achieved with 20.25-diazacholesterol. But a replacement to such an extent in our experiments happened only rarely with triparanol.

Whenever the desmosterol percentage was in the range between 40 to 60 percent (indicated in fig. 4 by shading) typical myotonic runs were not found but some short lasting spontaneous activity could clearly be seen.

The observation that the kinetics of cholesterol replacement by desmosterol is slower in slow-twitch muscles (fig. 6) than in fast-twitch muscles (fig. 4) fits well with the finding that after treatment with azacholesterol ${ }^{*}$ myotonia appears later in slow-twitch than in fasttwitch muscles (14).

From results concerning transport ATPases $(15,16,17)$ we have some evidence that the observed myotonia after treatment with 20.25-diazacholesterol is due to an alteration in the muscle cell membrane itself and is not secondary or neurogenic. The results reported in this paper support this assumption for at the time my otonia becomes evident in muscle only small changes in the sterol fraction of the peripheral nerve (fig. 7) and the brain (fig. 8) can be observed. There are no differences with regard to the desmosterol percentage in nervous tissue between 20.25-diazacholesterol treated rats being myotonic and those fed additionally a cholesterol rich diet not showing any signis of myotonia. In addition these findings show that 20.25-diazacholesterol itself is not the cause of the observed myotonia. 


\section{Acknowledgments}

This study was supported by Deutsche Forschungsgemeinschaft Bonn-Bad Godesberg and the Sonderforschungsbereich 90 of the University of Heidelberg.

\section{References}

1. Counsell, R. E., Klimstra, P. D. \& Ranney, R. E. (1962), J. Med. Pharm. Chem. 5, 1224-1233.

2. Winer, N., Martt, J. M., Somers, J. E., Wolcott, L., Dale, H. E. \& Burns, T. W. (1965), J. Lab. Clin. Med., 66,, 758-769.

3. Seiler, D. \& Kuhn, E. (1971), this j., 9, 245-248.

4. Blohm, T. R. \& Mac Kenzie, R. D. (1959), Arch. Biochem. Biophys., 85, 245-249.

5. Bricker, L. A., Weis, H. J. \& Siperstein, M. D. (1972), J. Clin. Invest. 51, 197-205.

6. Anderson, P. C. \& Martt, J. M. (1965), Arch. Dermat., 92, $181-183$.

7. Burns, T. W., Dale, H. E. \& Langley, P. L. (1965), Amer. J. Physiol., 209, 1227-1232.

8. Winer, N., Klachko, D. M., Baer, R. D., Langley, P. L. \& Burns, T. W. (1966), Science, 153, 312-313.

9. Sperry, W. M. (1955), Meth. Biochem. Anal., 2, 83-91.
We thank Miss 1. Geldmacher, Miss H. Göttig and Mrs. M. Wagner for skilful technical assistance.
10. Zak, B. (1957), Amer. J. Clin. Pathol., 27, 583-588.

11. Peter, J. B., Barnard, R. J., Edgerton, V. R., Gillespie, C. A \& Stempel, K. E. (1973), Biochemistry, 11, 2627-2633.

12. Fiehn, W. \& Peter, J. B. (1973), Exp. Neurol., 39, 372-380.

13. Peter, J. B. \& Fiehn, W. (1973), Science, 179, 910-912.

14. Eberstein, A. \& Goodgold, J. (1969), Experientia, 25, 1269-1270.

15. Fiehn, W., Kuhn, E. \& Geldmacher, I. (1973), FEBS-Lett., 34, 163-164.

16. Peter, J. B., Andiman, R. M., Bowman, R. L. \& Nagamoto, T. (1973), Exp. Neurol., 41, 738-744.

17. Fiehn, W., Seiler, D., Kuhn, E. \& Bartels, D., J. Clin. Invest. (in press)

Priv.-Doz. Dr. Dr. Dieter Seiler Med. Poliklin. d. Univ.

69 Heidelberg

Hospitalstr. 3 


\section{.}

